\title{
Improvement of Mechanical Properties of 3d Printed Hydroxyapatite Scaffolds by Polymeric Infiltration
}

\author{
Stevanovic $\mathbf{S}^{1 *}$, Chavanne $\mathbf{P}^{1}$, Braissant $\mathbf{O}^{2}$, Pieles $\mathbf{U}^{1}$, Gruner $\mathbf{P}^{3}$ and Schumacher $\mathbf{R}^{1}$ \\ ${ }^{1}$ FHNW - University of Applied Sciences and Arts of Northwestern Switzerland, Gründenstrasse 40, 4132 Muttenz, Switzerland \\ ${ }^{2}$ LOB2 - Laboratory of Biomechanics \& Biocalorimetry, University of Basel, Klingelbergstrasse 50-70, 4056 Basel, Switzerland \\ ${ }^{3}$ Medicoat AG, Almuesenacherstrasse 2, 5506 Mägenwil, Switzerland
}

\begin{abstract}
Tailor made bioceramic scaffolds in combination with the corresponding surface chemistry and biology is of great importance for a successful implantation and rapid osseo-integration. The present study investigates the fabrication of Hydroxyapatite (HA) scaffolds with defined macro porosity by means of powder based 3D-printing. In order to mime natural bone with its elastic collagen structure, the 3D-printed ceramic structures were post-treated by polymeric infiltration. Compressive Strength analysis (CS) confirmed the positive impact of an elastomeric phase on mechanical properties. 3D-printed HA scaffolds in combination with polymer result in biodegradable scaffolds with promising mechanical properties for potential use in regenerative medicine.
\end{abstract}

Keywords: 3D-printing; Hydroxyapatite; Polymeric infiltration; Scaffolds; Compressive strength

\section{Introduction}

Research on biomaterials for bone replacement has expanded considerably over the last decades. The required properties for ideal artificial bone material are best described as biocompatibility, biodegradability as well as bone adapted mechanical properties; in short, the graft should closely mimic the natural bone [1]. Bioceramics such as HA has been intensively investigated as a bone substitute due to its similar osteo-conductivity to bone [2]. Either HA material comes from natural or synthetic sources it possesses excellent biocompatibility in contact with bones, teeth, skin, and muscles. Furthermore HA promotes faster bone regeneration as well as direct bonding to regenerated bones without intermediate connective tissues [3]. When grinded to powder, HA scaffolds can be additive manufactured using a 3D-printing system in combination with suitable binder solution. 3D-printing is a technology where a three dimensional component is created by layer by layer binding of a material. Compared with traditional ceramic processing methods, powder based 3D-printing allows the production of tailor made implants with high biomimetic properties. In order to improve the mechanical properties of 3D-printed HA scaffolds, nature was mimed by adding an elastomeric component to the brittle ceramic structure. Such hybrid structures were achieved by infiltration of the 3D-printed and sintered HA scaffolds with biodegradable polymers like gelatin, Polyvinyl Alcohol (PVA) or Polycaprolactone (PCL). Gelatin satisfies most of the requirements of organic phase of a native bone due to its good mechanical properties, low toxicity and predictable biodegradation kinetics. Further practical advantages of gelatin make it an interesting candidate as it is readily available, comparatively cheap, dispersible in water and can be applied as thin coatings [3,4]. Biodegradable polymers like PCL or PVA exhibit the advantages of easy processing, low-processing costs and controlled biodegradability. Amongst them, PVA hydrogels have proven to be a promising class of material for osteochondral repair, since their physical as well as their chemical characteristics can resemble that of the articular cartilage and the subchondral bone [5]. In this study the flexibility and cost-effectiveness of biodegradable polymers was combined with the bioactivity and osteo-conductivity of HA to generate scaffolds for potential use in regenerative medicine. The positive impact of the elastomeric phase on the mechanical properties was confirmed by CS measurements.

\section{Materials and Methods}

\section{Materials}

Hydroxyapatite with a bimodal distributed grain size of $25 \mu \mathrm{m}$ and was 45 used from Medicoat AG (Mägenwil, Switzerland). Phosphoric acid (Aldrich) and citric acid (Sigma-Aldrich) were used during the 3D-printing process. To perform the infiltration process gelatin (Fluka), polyvinyl alcohol (Aldrich), polycaprolactone (Aldrich) and ethyl acetate (Sigma-Aldrich) were used.

\section{Production of specimens}

For powder based 3D-printing an adapted printing system (Z-Corp, Z-510) was applied to produce HA specimens with open porous structures, (Figure 1). As binder liquid an acidic solution (15 wt.\% phosphoric acid, 10 wt.\% citric acid) was used. After the printing process the specimens were dried at room temperature and afterwards sintered at $1425^{\circ} \mathrm{C}, 1 \mathrm{~h}$.

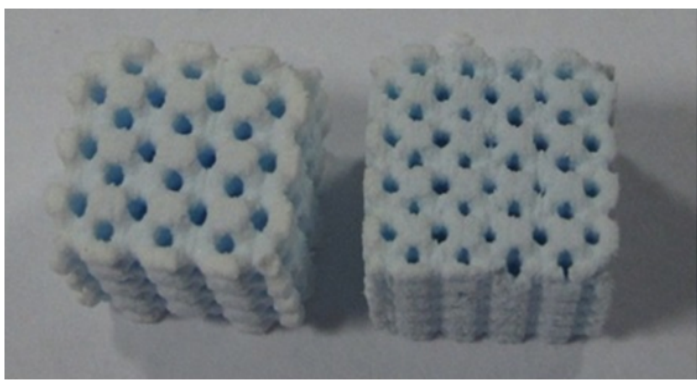

Figure 1: (A) Picture of two different open porous structures

*Corresponding author: Sabrina Stevanovic, FHNW - University of Applied Sciences and Arts of Northwestern Switzerland, Gründenstrasse 40, 4132 Muttenz, Switzerland, E-mail: sabrina.stevanovic@fhnw.ch

Received June 17, 2013; Accepted July 04, 2013; Published August 27, 2013

Citation: Stevanovic S, Chavanne P, Braissant O, Pieles U, Gruner P, et al. (2013) Improvement of Mechanical Properties of 3d Printed Hydroxyapatite Scaffolds by Polymeric Infiltration. Bioceram Dev Appl S1: 012. doi: 10.4172/2090-5025.S1-012

Copyright: (c) 2013 Stevanovic S, et al. This is an open-access article distributed under the terms of the Creative Commons Attribution License, which permits unrestricted use, distribution, and reproduction in any medium, provided the original author and source are credited. 
Citation: Stevanovic S, Chavanne P, Braissant O, Pieles U, Gruner P, et al. (2013) Improvement of Mechanical Properties of 3d Printed Hydroxyapatite Scaffolds by Polymeric Infiltration. Bioceram Dev Appl S1: 012. doi: 10.4172/2090-5025.S1-012

Page 2 of 3

\section{Polymeric infiltration}

Sintered HA scaffolds were infiltrated with a gelatin (10 wt.\% in water), PCL (3.6 wt.\% in ethyl acetate) or PVA solution (4 wt.\% in water). The polymeric solution was poured over the specimens placed in a Büchner funnel into the cylinder and drawn through the perforated plate by low vacuum suction, illustrated in Figure 2. After the infiltration they were dried for $1 \mathrm{~h}, 30^{\circ} \mathrm{C}$. The infiltration process was repeated $4 \mathrm{x}$. Additional infiltration processes were done with PVA and gelatin up to $10 \mathrm{x}$.

\section{Analysis}

To analyse mechanical properties and surface structure, measurements of compressive strength (CS) (Hydropulser LFV-5-PA/ ECD 120, walter + bai ag), porosity by Archimedes (Tensiometer K100, Krüss) and scanning electron microscopy (SEM) (TM-1000, Hitachi) were performed.

\section{Results}

After the infiltration process the specimens showed a smooth, polymeric layer on the surface, (Figure 3). The SEM pictures, (Figure 4), showed HA crystals enclosed in polymeric component after infiltration. The enclosure with PVA and PCL was not as efficient as observed in case of gelatin. The CS of the 3D-printed open porous specimens averaged before infiltration $0.8 \mathrm{MPa}(\mathrm{s}=0.03)$. After $4 \mathrm{x}$ infiltration process with gelatin the CS increased to $3.7 \mathrm{MPa}(\mathrm{s}=0.01)$ and even more after $10 \mathrm{x}, 12.6 \mathrm{MPa}(\mathrm{s}=0.57)$, as illustrated in Figure 2. The CS values of $4 \mathrm{x}$ and 10x PVA infiltrated specimens increased to

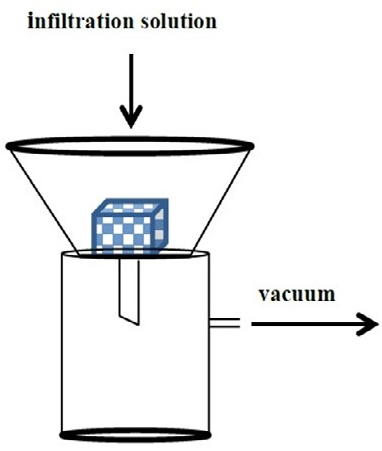

Figure 2: Draft of the infiltration process, in the middle the 3D-printed sintered HA scaffold (blue).

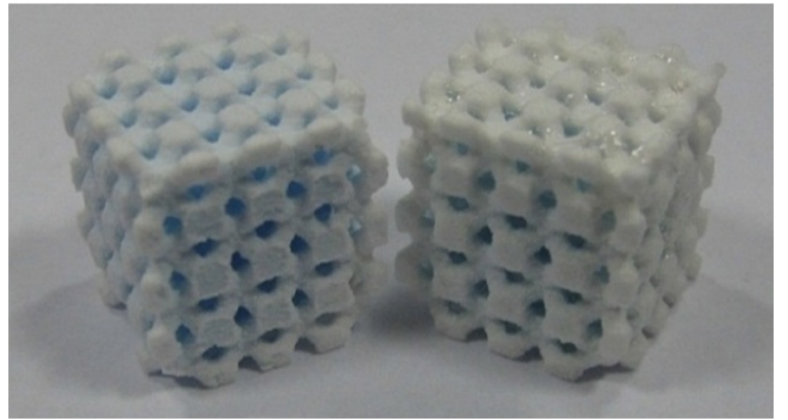

Figure 3: Picture of scaffold before infiltration (left) and scaffold after infiltration with PVA (right). On the treated scaffold a shiny, thin layer of PVA can be observed. $1.03(\mathrm{~s}=0.57)$ and $4.9 \mathrm{MPa}(\mathrm{s}=0.18)$ and the one of PCL up to $0.9 \mathrm{MPa}$ $(s=0.06)$ (Figure 5). Decrease of porosity was observed in all specimens after the infiltration. With gelatin the value decreased around 60\%, PVA $10-20 \%$ and PCL $2 \%$.

\section{Discussion and Conclusion}

The aim of this study was to combine biodegradable polymers with the bioactivity and osteo-conductivity of $\mathrm{HA}$ to generate scaffolds with improved mechanical properties. The scaffolds were fabricated with an adapted powder based 3D-printing method and a polymeric infiltration as post-treatment. In previous publications CS of 3D-printed composites with other bio polymers are reported in a range of $0.5-5 \mathrm{MPa}[5,6]$. With the developed infiltration approach after the sintering process, scaffolds reached CS values of up to $12 \mathrm{MPa}$ and a decreased porosity depending on the polymer solution and its concentration. The combination of gelatin and HA processed with an optimized 3D-printing and post-infiltration method resulted in customizable scaffolds with the most promising mechanical properties. Literature claims that higher stability can be attributed to crack bridging provided by the applied gelatin coating, which results in an increased compressive strength [7]. Moreover findings in the publication of Kim et al. suggest that gelatin- HA composites have high potential for use as a hard tissue scaffold [8]. However the insolubility of the specimens needs to be further improved to ensure mechanical stability in body like environments. Furthermore the primary infiltration approach is only applicable to the outermost layer. A reduction of this effect would additionally increase the compressive strength. The infiltration method is still in its infancy but bears high potential for drastically improving the mechanical properties of 3D-printed ceramic scaffolds. In addition

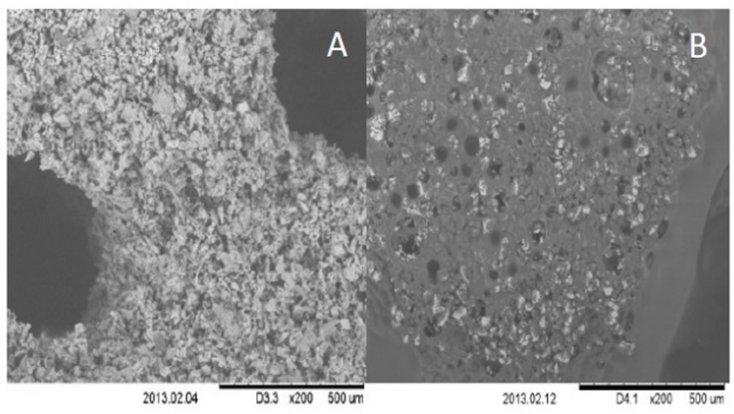

Figure 4: SEM image of 3D-printed HA before infiltration (A) and after 10x infiltration process $(B)$, the enclosing gelatin is clearly visible (smooth / dark region).

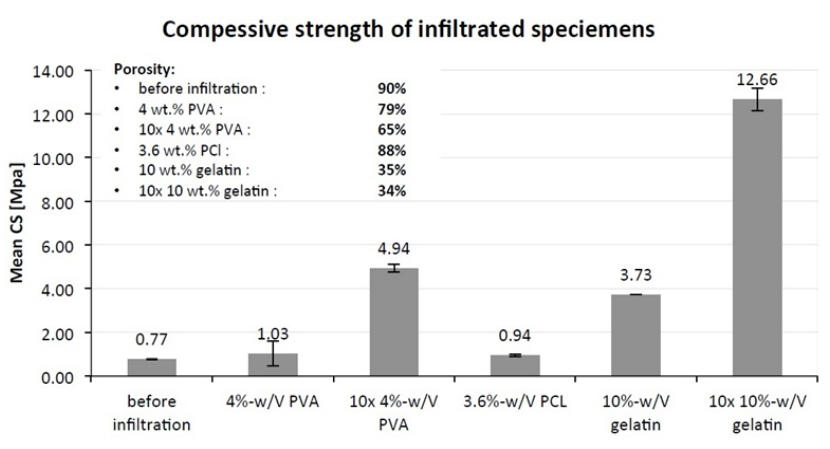

Figure 5: Compressive strength and porosity values of gelatin, PVA and PCL infiltrated open porous HA scaffold. 
Citation: Stevanovic S, Chavanne P, Braissant O, Pieles U, Gruner P, et al. (2013) Improvement of Mechanical Properties of 3d Printed Hydroxyapatite Scaffolds by Polymeric Infiltration. Bioceram Dev Appl S1: 012. doi: 10.4172/2090-5025.S1-012

the developed infiltration method establishes new possibilities for integration of bioactive compounds like bone collagen or anti-infective agents such as antibiotics or silver/copper ions.

\section{Acknowledgement}

Support by the Swiss-Nanoscience Institute (SNI) and Swiss National Science Foundation (SNSF) is gratefully acknowledged.

\section{References}

1. YaylaoÄŸlu MB, Korkusuz P, Ors U, Korkusuz F, Hasirci V (1999) Development of a calcium phosphate-gelatin composite as a bone substitute and its use in drug release. Biomaterials 20: 711-719.

2. Venkatesan J, Kim SK (2010) Chitosan composites for bone tissue engineering-an overview. Mar Drugs 8: 2252-2266.

3. Kailasanathan C, Selvakumar N (2012) Comparative study of hydroxyapatite/ gelatin composites reinforced with bio-inert ceramic particles. Ceram Int 38: 3569-3582.
4. Batista NA, Rodrigues AA, Bavaresco VP, Mariolani JRL, Belangero WD (2012) Polyvinyl Alcohol Hydrogel Irradiated and Acetalized for Osteochondral Defect Repair: Mechanical, Chemical, and Histological Evaluation after Implantation in Rat Knees. Int J Biomat 582685.

5. Butscher A, Bohner M, Hofmann S, Gauckler L, Müller R (2011) Structural and material approaches to bone tissue engineering in powder-based threedimensional printing. Acta Biomater 7: 907-920.

6. Ryter, N, Koeser J, Hoffmann W, Pieles U, Jung C, et al. (2011) Annual Meeting of the Swiss Society for Biomedical Engineering (SSBE), Bern August 22-23, 2011.

7. Dressler M, Dombrowski F, Simon U, Börnstein J, Hodoroaba VD, et al. (2011) Influence of gelatin coatings on compressive strength of porous hydroxyapatite ceramics. J Eur Cer Society 31: 523-529

8. Kim HW, Kim HE, Salih V (2005) Stimulation of osteoblast responses to biomimetic nanocomposites of gelatin-hydroxyapatite for tissue engineering scaffolds. Biomaterials 26: 5221-5230.
This article was originally published in a special issue, International Symposium on Apatite and Correlative Biomaterials handled by Editor(s). Dr. Guy Daculsi, ISCM General secretary, France.

Citation: Stevanovic S, Chavanne $\mathrm{P}$, Braissant $\mathrm{O}$, Pieles $\mathrm{U}$, Gruner $\mathrm{P}$, et al (2013) Improvement of Mechanical Properties of 3d Printed Hydroxyapatite Scaffolds by Polymeric Infiltration. Bioceram Dev Appl S1: 012. doi: 10.4172/2090-5025.S1-012 